\title{
Nominations of Molecular Cuisine Dishes: Lexical, Syntactic and Semantic Analysis
}

Olga Novikova, ${ }^{+*}$ Gulnara Garipova, ${ }^{\dagger}$ and Zulfiya Izimarieva ${ }^{+}$

\section{Abstract}

Non-traditional foods of molecular cuisine are a new category of foods and experience for consumers. The objective of this study was to conduct the structural and semantic analysis of the names of dishes of this new scientific field and avant-garde culinary practice. The main idea was to reveal the trend and trace the dynamics of naming dishes and to define the degree of reflecting the essence of molecular cuisine in the names of dishes. The study of empirical material taken from current collections of recipes and restaurant menus using a set of linguistic analysis methods has allowed authors to identify models of the syntactic organisation of nominations; characterise the primary way of connecting their components as oxymoron; highlight a number of keywords that arrange these nominations on the basis of cooking technology into several subject groups; postulate the predominance of phrase-names with transparent semantics over names with an opaque inner form including eponymous nominations; outline the ways of further studying the names of dishes of this cuisine from comparative, translational and linguistic-cognitive points of view.

Keywords: Molecular Cuisine; Linguistic Nomination; Structural, Lexical and Semantic Analysis; Gastronomic and Cultural Traditions

\footnotetext{
${ }^{\dagger}$ Bashkir State Agrarian University, Russian Federation

* Corresponding Author, Email: nowikowa.Olha@gmail.com

(C) 2019 Novikova et al. This is an Open Access article distributed under the terms of the Creative Commons Attribution License (http://creativecommons.org/licenses/by/2.0), which permits unrestricted use, distribution, and reproduction in any medium, provided the original work is properly cited.
} 


\section{Introduction}

Over recent years gastronomy has been increasingly recognised as an essential part of a culture, and food has emerged as a great tool for communication with other people and communities (Atkins \& Bowler, 2016; Magar \& Kar, 2016). Food and culinary practices become more and more interdisciplinary integrating chemistry, physics, management, theory of communication and sign systems, cognitive psychology, and anthropology. Linguistic studying of food phenomenon as one of the most important factors of human life and activities is relatively new and is concentrated around several research plots: 1) in cultural linguistics the traditions of national cuisines are shown to serve as cultural codes reflected in linguistic facts constituting a fragment of national linguistic and value-based world picture (Civitello, 2008; Montanari, 2006; Chiaro \& Rossato, 2015). Their comparison from the cognitive point of view is conducted on different linguistic communities; 2) the numerous research revolves around gastronomic discourse as being the person-oriented kind of communication, which is of institutional nature. Along with the spheres of food concepts it is connected with national and personal selfidentification, gender and personal social characteristics and is studied in cognitive, pragmatic, and semiotic aspects according to the level of organisation and representation in other discourses (Parizot, 2015; Fooladi et al., 2019); 3) psychological and pragmatic impact of food nomination is analysed in sociology, cultural anthropology, economy (Cardello et al., 2012; Cho, 2019; Wansink et al., 2005; Wansink et al., 2012; Wansink et al., 2014; Youn \& Kim, 2017; Youn \& Kim, 2018). Names of dishes as linguistic signs loaded with cultural information and actively functioning in different discourses lie at the core of all plots.

The objective of the research is to define linguistic peculiarities of the names of dishes of the new trend in gastronomy and to reveal its idio-ethnic and universal characteristics. The topicality of the research is due to the attention of linguists, representatives of humanitarian and non-humanitarian knowledge to the national and cultural specific character of language, its representation in such a significant fragment as gastronomic discourse as well as the growing interest in the economic function of the language. Facts from different life spheres such as identity crisis, the emergence of new culinary practices, growth of gastronomic tourism, neotrends in science and technology, increased competition in the economy and as a consequence search for Self and new strategies in the dialogue with Others and the World contribute to the validity of the investigation.

The novelty of the research lies in interpreting the names of the dishes of the new gastronomic dimension as a terminology of new science. The word 'new' in inverted commas makes sense as this cuisine takes traditional, natural ingredients and products and studies the physical and chemical processes which occur during cooking. Thus, molecular cuisine can be considered as a part of triphology or food science in narrow sense, but for most people it is a new avantgarde cuisine (This, 2013). Experts in this field call it differently emphasising this or that peculiarity: culinary constructivism, emotional cuisine, modern cuisine, cuisine science, technocuisine, and others.

So, the rationale of reaching the objective implies the successive solving of the following tasks:

- study of the state of knowledge of the issue;

- collecting the empiric materials;

- syntactic, lexical and semantic analysis of the materials;

- classification of the materials;

- outlining the work perspectives.

The research begins with a discussion of the methods. It then goes on to discuss the review of literature. Critical analysis of the results is presented in the sections following this. 


\section{Methods}

The objective and the tasks define the choice of methods on each step of the research:

- descriptive method as the primary method in linguistics for collecting, interpreting and summarising the data on the studied units. At the same time, the involvement of the data of other sciences makes the research more explanatory;

- inductive-deductive. The inductive method consists of collecting and registering specific phenomena (facts) with their subsequent generalisation and transition from facts to the underlying entities. The deductive method as a starting point implies the postulation of entities based on certain assumptions and verification of the reality of these entities by their correspondence (or discrepancy) to the observed facts. The most productive way is the alternate the use of the deductive and inductive methods with the successive refinement of the concept of the object studied: at the initial stage, some hypotheses about linguistic entities are deductively put forward and then they are inductively tested in the process of empirical work with the observed language material. The discrepancy revealed between the postulated entities and the inductively obtained generalisations, in this case, requires the next cycle of a new deductive scheme and their subsequent inductive testing;

- semantic and syntactic analysis, that is, selection of keywords from the issue that characterise the subject and aspects - structural analysis; the subsequent identification of their semantic content semantic analysis;

- IC analysis of the components themselves, or the representation of the word combination syntactic structure from the whole structure to its components, makes it possible to establish a hierarchy of relations in it. A word-combination is characterised by completeness / incompleteness, headword, syntactic relations and the way of linkage between the components:

- elements of the component analysiswith the characteristic of oxymoron combinations. The semantic structure of words is subject to component analysis in such a way that each word is decomposed into semes independently from others based on dictionary definitions;

- the comparative analysis is necessary to identify the universal and idioethnic features of the studied nominations.

The number of single linguistic facts is infinite; they are necessary only as carriers of the essential properties of language, the identification of which can be bidirectional: from facts to entities or from entities to facts. The study material included 860 names of dishes selected by the method of continuous sampling from the menus of restaurants and collections of molecular cuisine recipes in Europe, Asia, America in Russian and English (see: Sources of material).

The hypothesis of the research is that the names of molecular cuisine dishes reflect its essence, specificity and goals which correlate with The Lima Declaration of the leading chefs of the world: the present and future of culinary art is discerned visually in the commitment to the gifts of nature and eco-friendly agriculture; cooking is positioned as a part of culture that plays an essential role in the formation of personal, regional and national identity enhancing intercultural interaction; it aims at creating new knowledge and acts as a means of self-development (The Lima Declaration: Open Letter to the Chefs of Tomorrow). 


\section{Literature Review}

Language and national gastronomy are regarded as a certain type of language identity, functioning in specific communicative ways of information exchange. Universal, ethnic and cultural ways of gastronomic's verbalising are related to the specific type of categorisation of reality. Food and its uses furnish setting and structure for language, just as language and its uses constrain and inform food activities (Karrebæk et al., 2018). The present work relies upon the results of studying the impact of the product name (in the global sense of the word) which is currently the spotlight of researchers in the sphere of consumption including psychologists, marketing experts, and brand makers.

Numerous studies have shown that the name of a food product influences its perception as belonging to a particular national cuisine (Youn \& Kim, 2017; Youn \& Kim, 2018). Only the name of food can indicate its peculiarity and its distinction from another product which cannot be assessed visually since a word activates an associative chain that causes a more powerful cognitive-affective and emotional response than the food itself (Cardello et al., 2012). The names of dishes serve as a tool for identifying personal but socially conditioned propensity for a special diet at the perceptual, hedonic, and emotional levels (Cho, 2019; Loss et al., 2017). At the same time, neophyles, or foodies, can refuse a utterly innovative product because of its 'novel foods' unusual uniqueness (Loss et al., 2017). 'Uniqueness' is attractive; it is considered as a component of luxury as it connotes exclusiveness and rarity, and the possession of it, respectively, increases the social status of the individual (Snyder \& Fromkin, 1982). The impact of the phonetic and morphological aspects of a name as a linguistic sign is beneficial if the word is easily pronounced, and, on the contrary, the product is perceived as less useful and acceptable if its name is difficult to pronounce (Cho, 2019; Song \& Schwarz, 2009). The value of food in the eyes of the consumer increases if the composition of its ingredients is indicated (Wansink et al., 2005; Wansink et al., 2014).
Thus, the study of names of dishes is focused on their pragmatic effects as the names appear to be the essential constituents contributing to customers' perceptions of the dish and their purchase intentions.

Literature searches have shown that molecular cuisine remains a peripheral area of linguistic studies, although the main characteristic of any academic discipline is its own terminology. In this case, the basic terms include the names of dishes which act as an interface between the producer and the consumer differing in terms of language from the names of dishes of other cuisines and having specific communicativepragmatic meaning.

\section{Results and Discussion}

The names of dishes, as well as all proper names, are the result of secondary naming: 'in the nomination act the phonetic image of the existing unit is used as the name for the new designated' (Golomidova, 2003: 110). The results of such a nomination are perceived as derived units by morphological composition or meaning. The methods of secondary naming differ depending on the language means involved in the creation of new names and on the nature of the 'name-reality' correlation.

Analysis of names of molecular cuisine dishes shows that for the most part they are represented by complete noun word combinations with a noun headword. As far as syntactic relations are concerned, attributive multi-component compositional and subordinate combinations with different arrangement of the defined and defining words prevail here, cf.: pea spheres, Smoked Beer-preposition; Oysters Topped with Fruit Caviar post-position; Strawberry Spheres with Ground Pepper; Raspberry Caviar with Strawberry Foam And Caramel - combination of pre- and postposition. It should be noted that, since there can be more than two components in a word combination, some of them can be attached to the previous one by asyndeton, and the others by syndesis. This is the way coordinate and subordinate word-combinations of mixed syndetical and asyndetical structure are formed, cf.: Red Beet with Cheeses and Powdered 
Walnut; Vegan Scallops with Carrot Ginger Caviar.

English nominations are substantive wordcombinations with an attributive link; in Russian word-combinations, the components are determined both by attributive and objective links. In the course of the study, it was established that in the expression the components of word-combinations are nouns, adjectives and participles; adverbs and numerals are represented by isolated cases, cf.: Charcoal, Ashes and a $64^{\circ} \mathrm{Egg}$ - the numeral indicates the temperature of cooking eggs using sous-vide technology. In English, non-prepositional models dominate; in Russian, with an increase in the number of components, the number of prepositional models grows up. This is explained by the fact that each language coins its own individual word-combinations, primarily determined by the nature of the language itself with the consistency of the content plane. The bonding of components within wordcombinations is brought about using syntactic means available in each national language.

Component analysis reveals the primary way of predicating the studied combinations oxymoron. Oxymorons, being a robust stylistic device, are not uncommon in scientific terminology, cf.: white black (carbon), infinite limit, liquid nails, liquid gas, dry wine, dry alcohol. There is no logical contradiction because one of the words in such word-combinations attains phraseologically-bound meaning; cf.: in the word-combination 'dry wine', the designation indicates that sugar is fermented completely in wine, that is, 'to dryness'. In an oxymoron, which is usually a combination of definition and defined, the core is the name of a traditional dish of a particular cuisine. Paradox, illogicality is manifested in its new characterisation through - innovative cooking process, cf.: Exploding Borsch: explode 'to undergo an explosion, to collapse from an explosion' (Oxford Reference English Dictionary), borsch is highly seasoned Russian or Polish soup with different ingredients including cabbage and beetroot and usually served with sour cream (Oxford Reference English
Dictionary); unexpected combination of ingredients, cf.: Hot Ice Tea: hot - 'having a relatively high temperature' (Oxford Reference English Dictionary), ice - 'frozen water' (Oxford Reference English Dictionary) tea. It should be noted that nomination through oxymoron correlates with such a specialism of the molecular cuisine as unconventional traditional food, cf.: vinegret (Russian Salad): a cold snack dish of mixed vegetables with dressing - beets are served as a jelly, a mixture of vegetables - in the form of foam, dressing - as an emulsion. Cognitive dissonance which is typical for molecular cuisine is achieved not by traditional name but through the layout of the dish.

Descriptive names of dishes represented by detailed word-combinations bring together the nomination processes of molecular and ethnic cuisines. As the studies of the latter have shown, the unusual name enhances both the interest in the dish and its perception as authentic and risk in its relation, but attractiveness prevails (Youn \& Kim, 2017; Youn \& Kim, 2018) which gives grounds to recommend them for active practical application. However, unlike national cuisines, in molecular cuisine there are very few nominations with an opaque inner form; providing information neither about the composition of the dish nor about the technology of its preparation, they differ in the degree of emotional and expressive colouring of the components, (see Table 1).

The eponymous names were also included into that group; proper names-anthroponyms (names of outstanding scientists) were used in naming the pioneer dishes of the new cuisine (This, 2013): Gibbs - egg white with sugar and olive oil in the form of jelly - in honour of J. W. Gibbs (Josiah Willard Gibbs, 1839-1903 ); Vauquelin - fruit foam - named after N. Vauquelin (Nicolas Vauquelin, 1763-1829); Baumé - an egg cooked in alcohol - in memory of A. Baumé (Antoine Baumé, 1728-1804). However, this list is not updated; the semantics of the identified name Peruvian Inspired Filet Mignon with a Japanese Twist is transparent just because of its toponymic components. 
Analysis of the lexical content of syntactic structures has revealed the main feature of the molecular cuisine - the use of a number of words (let's call them keywords) that are not found in the names of dishes from other culinary trends.
Keywords can be divided into several thematic groups, that is, associations of nominations based on external relations between denotations according to the cooking technology principle, (see Table 2).

\begin{tabular}{|c|c|c|}
\hline $\begin{array}{l}\text { Name of the } \\
\text { Dish }\end{array}$ & Dish ingredients & Source \\
\hline $\begin{array}{l}\text { New Ocean and } \\
\text { Mountain }\end{array}$ & $\begin{array}{l}\text { Tomatoes, red pepper, } \\
\text { raviolis, green onion stalks }\end{array}$ & $\begin{array}{l}\text { Chef Digilio's restaurant, 'La Vineria de } \\
\text { Gualterio Bolivar', Buenos Aires, Argentina }\end{array}$ \\
\hline Black Forest & $\begin{array}{l}\text { A deconstructed black forest } \\
\text { dessert made at the table } \\
\text { with dark chocolate mousse, } \\
\text { white chocolate mousse, } \\
\text { trees made with a stick of } \\
\text { dark chocolate and foliage of } \\
\text { cotton candy, soil of coffee } \\
\text { and cocoa, white chocolate } \\
\text { sticks, sweet cherries } \\
\text { marinated in alcohol, cherry } \\
\text { sauce, icing sugar, chocolate } \\
\text { covered maraschino } \\
\text { cherries. }\end{array}$ & $\begin{array}{l}\text { Georgianna Hiliadaki and Nikos Roussos, } \\
\text { Athens, Greece }\end{array}$ \\
\hline $\begin{array}{l}\text { Cashews in a } \\
\text { Bag }\end{array}$ & $\begin{array}{l}\text { Edible bag made with ultra- } \\
\text { thin edible film }\end{array}$ & $\begin{array}{l}\text { Georgianna Hiliadaki and Nikos Roussos, } \\
\text { Athens, Greece }\end{array}$ \\
\hline $\begin{array}{l}\text { Orange } \\
\text { explosion }\end{array}$ & $\begin{array}{l}\text { White chocolate spheres } \\
\text { with orange filling }\end{array}$ & $\begin{array}{l}\text { Georgianna Hiliadaki and Nikos Roussos, } \\
\text { Athens, Greece }\end{array}$ \\
\hline Dangerous lamb & Peas, celeriac, teriyaki & Tapas molecular bar, Tokyo, Japan \\
\hline $\begin{array}{l}\text { Molecular } \\
\text { cocktail "Space } \\
\text { creature brains" }\end{array}$ & Bailey's and Blue Curasao & $\begin{array}{l}\text { Master classes on molecular culinary, Russia, } \\
\text { Moscow } \\
\text { https://molecularmeal.ru/nashi_uslugi/bljuda }\end{array}$ \\
\hline
\end{tabular}

Traditionally used words in the function of keywords in the new context modify their meaning, cf.: noodle - a strip or ring of pasta; spaghetti - pasta made in solid strings (Oxford English Reference Dictionary). In molecular gastronomy, these words indicate solely the shape of the dish, but not its ingredients: orange spaghetti, spinach pesto spaghetti; silicone tubes and a syringe are used for their preparation.

A dish can be the result of a combination of different technologies which is also reflected in the name, cf.: Stuffed Morels, Thyme Air, Port
Gel, Oak Moss Dry Ice Vapour. According to $\mathrm{H}$. This's opinion, the use of 4 basic technologies and 6 phases of preparation yields more than $10^{6}$ innovations (what does it mean. Explain in footnote in a line or two (This, 2013); however, as distinct from unlimited variations of creating dishes, their names are formed according to a limited inventory of structural models. From the semantic point of view, the stability of a word combination is a means of forming and fixing the concept as a part of a particular system of knowledge which determines its reproducibility. Word-combinations - names of dishes reflect an integral but unified concept in the system of 
concepts of molecular cuisine as a scientific and the name-phrase is, first of all, a means of culinary sector of activity. The individual forming and fixing the concept as a part of a components of a multi-word unit express the particular knowledge system. essential features of a concept. The stability of

\begin{tabular}{|c|c|c|}
\hline Technology & Name of the Dish & Keywords \\
\hline $\begin{array}{l}\text { 1. Spherification } \\
\text { Making the finished product in the form } \\
\text { of sphere }\end{array}$ & $\begin{array}{l}\text { Plum Caviar with Basic } \\
\text { Spherication, } \\
\text { Cocktail ice sphere }\end{array}$ & $\begin{array}{l}\text { Caviar, crystal, } \\
\text { foam, infusion, } \\
\text { pearl, sphere, } \\
\text { spherification }\end{array}$ \\
\hline $\begin{array}{l}\text { 2. Gellification } \\
\text { Processing of the product into gel using } \\
\text { agar-agar, alginate or gelatin }\end{array}$ & $\begin{array}{l}\text { Olive Oil Butter' and Balsamic } \\
\text { Vinegar Gel, } \\
\text { Balsamic Vinegar Pearls }\end{array}$ & $\begin{array}{l}\text { Gel, jelly, } \\
\text { noodle*, } \\
\text { spaghetti* }\end{array}$ \\
\hline $\begin{array}{l}\text { 3. Foams } \\
\text { Turning the product into foam using } \\
\text { soya lecithin, protein powder as } \\
\text { thickeners }\end{array}$ & $\begin{array}{l}\text { Apple Caviar with Banana Foam, } \\
\text { Espresso Pasta \& Foam With } \\
\text { Chocolate Sponge Cake }\end{array}$ & $\begin{array}{l}\text { Espuma, foam, } \\
\text { sauce }\end{array}$ \\
\hline $\begin{array}{l}\text { 4. Emulsification } \\
\text { The way of turning product into } \\
\text { emulsion where fat and water are not } \\
\text { mixed }\end{array}$ & $\begin{array}{l}\text { Saffron Crème Anglaise with } \\
\text { Coffee Air, } \\
\text { Lychee Bubbles Filled with Sage, } \\
\text { Vapour on Oysters }\end{array}$ & $\begin{array}{l}\text { Air, bubble, } \\
\text { crème, mousse, } \\
\text { powder, sauce, } \\
\text { vapour }\end{array}$ \\
\hline $\begin{array}{l}\text { 5. Sous vide technology } \\
\text { Vacuum cooking technology where } \\
\text { products in vacuum pack are double } \\
\text { boiled at low controlled temperature } \\
\text { over a long period of time }\end{array}$ & $\begin{array}{l}\text { 'Sous vide' steak, } \\
\text { Chicken Kiev 'Sous Vide' with } \\
\text { mashed smoked potatoes and } \\
\text { lemon confiture }\end{array}$ & Sous vide \\
\hline 6. Smoking & $\begin{array}{l}\text { Smoked Butter with Sherry, } \\
\text { Vinegar Jelly, } \\
\text { Smoked Spinach Salad }\end{array}$ & Smoked \\
\hline $\begin{array}{l}\text { 7. Low-temperature method } \\
\text { Cooking using dry ice and liquid } \\
\text { nitrogen }\end{array}$ & $\begin{array}{l}\text { Red Cabbage Gazpacho with } \\
\text { Grain Mustard Ice Cream, } \\
\text { Yogurt Snow }\end{array}$ & Frost, ice, snow \\
\hline
\end{tabular}

\section{Conclusion}

The analysis of the names of the dishes of molecular cuisine in Russian and English has revealed a universal tendency of nomination the predominant use of words and wordcombinations with transparent inner form. 'Nationality' of dishes is defined by naming components that indicate a particular national cuisine or are stereotypically associated with it. Structural and semantic analysis has shown that the names of molecular cuisine dishes reflect its goals: creating a new recipe, testing 'old wives' recipes, considering the art of cooking from the point of view of science and social practice taking into account its heuristic role. Names of dishes are word-combinations formed on the attributive or objective model; they reflect the method of cooking, taste and ingredients of the dish. From the semantic point of view, most of them are oxymorons - word-combinations characterised by a violation of typical notional combinability leading to a special interaction of the subject-logical and emotional meaning of its components. The eponymous names of dishes imply an appeal to the structures of knowledge that stand behind the proper name; they are 
extremely few, as are the names with an opaque inner form. According to the structural and semantic principle, several groups can be distinguished in the material studied: 1 ) the names of novel dishes reflecting innovative cooking technologies and divided into seven subgroups, respectively, with their own keywords; these nominations are descriptive and have transparent semantics; 2) the traditional names of the original dishes; 3 ) author's nominations with opaque semantics including eponymous names. In the absence of a language oxymoron, cognitive dissonance arises from the visual appearance and way of serving dishes of Groups 2 and 3.

The practical value of the study is that it contributes to the theory and practice of language nomination of the current segment of consumer and professional human activity identifying universal and idio- ethnic criteria in it and highlights work prospects: statistical analysis of types of nominations and the dynamics of naming trends as regards interaction with ethnic and haute cuisine; spelling norms of the considered language units; their comparative cross-lingual analysis including translational and linguistic-didactic aspects although, however, certain associative and conceptual background lacunae are inevitable since with a general technological foundation the molecular cuisine addresses the consumer in a particular country with its own cultural and gastronomic traditions. The results gained yield certain managerial implications since the success of a new cuisine depends on the names of its foods.

\section{References}

Atkins, P., \& Bowler, I. (2016). Food in society: economy, culture, geography. Routledge. p. 344

Cardello, A.V., Chheang, S.L., Hedderley, D.L., Guo, L.F., Jaeger, S.R. (2019). Toward a new scale to measure consumers" "need for uniqueness" in foods and beverages: the 31-item FBNFU scale. Food Quality and Preference, 72, pp. 159-171.
Cardello, A.V., Meiselman, H.L., Schutz, H.G., Craig, C., Given, Z., Lesher, L.L., Eicher, S. (2012). Measuring emotional responses to foods and food names using questionnaires. Food Quality and Preference, 24(2), pp. 243-250.

Chiaro, D., \& Rossato, L. (2015). Food and translation, translation and food. The Translator, 21 (3), pp. 237-243.

Cho, H. (2019). Brand name fluency and perceptions of water purity and taste. Food Quality and Preference, 71, pp. 21-24.

Civitello, L. (2008). Cuisine and Culture: a History of Food and People. Hoboken: John Wiley \& Sons, p. 170.

Fooladi, E., Hopia, A., Lasa, D., Arboleya, J-C. (2019). Chefs and researchers: Culinary practitioners' views on interaction between gastronomy and sciences. International Journal of Gastronomy, 15, pp. 6-14.

Golomidova, M.V. (2003). The Pragmatical Aspect of Names' Creating Process: Conspectus. Onomastics and Dialect Lexics. Collection of research papers, Ekaterinburg, 4, pp. 107-120.

Jaeger, S.R., Cardello, A.V., Jin, D., Hunter, D.C., Roigard, C.M., Hedderley, D.I. (2017). Product uniqueness: Further exploration and application of a consumer-based methodology. Food Quality and Preference, 60, pp. 59-71.

Karrebæk, M.S., Riley, K.C., Cavanaugh J.R. Food and Language: Production, Consumption, and Circulation of Meaning and Value (2018). Annual keywords of Anthropology, 47, pp. 17-32.

Loss, C.R., Zellner, D., Migoya, F. (2017). Innovation influences liking for chocolates among neophilic consumers. International Journal of Gastronomy and Food Science, 10, pp. 7-10.

Magar, C. K., \& Kar, B. K. (2016). Tea Plantations and Socio-Cultural Transformation: The Case of Assam (India). Space and Culture, 
India, 4(1),

pp. https://doi.org/10.20896/saci.v4i1.188

Montanari, M. (2006). Food Is Culture. Columbia University Press, p. 168 p

Oxford Reference English Dictionary. Second edition. (1996). Oxford, New York: Oxford University Press.

Parizot, A. (2015). Gastronomy: between transparency and opacity. A game of lights and shades. Lexia, 19, pp. 65-79.

Snyder, C.R., Fromkin, H.L. (1982). Uniqueness. The Human Pursuit of Difference. New York and London: Plenum Press, pp. 267

Song, H., Schwarz, N. (2009). If it's difficult to pronounce, it must be risky: Fluency, familiarity, and risk perception. Psychological Science, 20(2), pp. 135-138.

The Lima Declaration: Open Letter to the Chef of Tomorrow.

This, H. (2013). Molecular gastronomy is a scientific discipline, and note by note cuisine is the next culinary trend. Flavour, 2, p. 18.
Wansink, B., Just, D.R., Payne, C.R., Klinger, M.Z. (2012). Attractive names sustain increased vegetable intake in schools. Preventive Medicine, 55(4), pp. 330-332.

Wansink, B., Tal, A., Brumberg, A. (2014). Ingredient-based food fears and avoidance: antecedents and antidotes. Food Quality Preference, 38, pp. 40-48.

Wansink, B., Van Ittersum, K., Painter, J.E. (2005). How descriptive food names bias sensory perceptions in restaurants. Food Quality and Preference, 16(5), pp. 393-400.

Youn, H., Kim, J.-H. (2017). Effects of ingredients, names and stories about food origin on perceived authenticity and purchase intentions. International Journal of Hospitality Management, 63, pp. 11-21.

Youn, H., Kim, J.-H. (2018). Is Unfamiliarity a double-edged sword for ethnic restaurants? International Journal of Hospitality Management, 68, pp. 23-31. 